\title{
Larval exposure to field-realistic concentrations of clothianidin has no effect on development rate, over-winter survival or adult metabolic rate in a solitary bee, Osmia bicornis
}

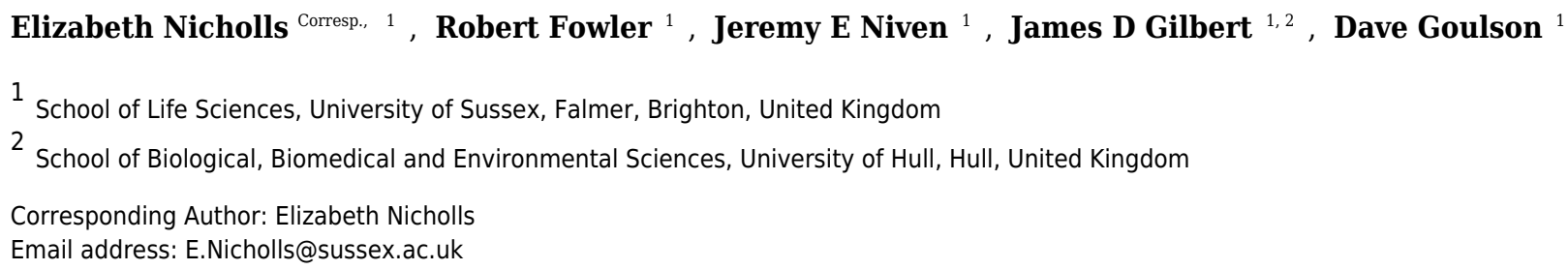

There is widespread concern regarding the effects of agro-chemical exposure on bee health, of which neonicotinoids, systemic insecticides detected in the pollen and nectar of both crops and wildflowers, have been the most strongly debated. The majority of studies examining the effect of neonicotinoids on bees have focussed on social species, namely honey bees and bumble bees. However, most bee species are solitary, their life histories differing considerably from these social species, and thus it is possible that their susceptibility to pesticides may be quite different. Studies that have included solitary bees have produced mixed results regarding the impact of neonicotinoid exposure on survival and reproductive success. While the majority of studies have focused on the effects of adult exposure, bees are also likely to be exposed as larvae via the consumption of contaminated pollen. Here we examined the effect of exposure of Osmia bicornis larvae to a range of field-realistic concentrations $(0-10 \mathrm{ppb})$ of the neonicotinoid clothianidin, observing no effect on larval development time, overwintering survival or adult weight. Flow-through respirometry was used to test for latent effects of larval exposure on adult physiological function. We observed differences between male and female bees in the propensity to engage in discontinuous gas exchange, however no effect of larval clothianidin exposure was observed. Our results suggest that previously reported adverse effects of neonicotinoids on $\mathrm{O}$. bicornis are most likely mediated by impacts on adults. 
1 Larval exposure to field-realistic concentrations of clothianidin has no effect

2 on development rate, over-winter survival or adult metabolic rate in a solitary

3 bee, Osmia bicornis

4 Elizabeth Nicholls ${ }^{1}$, Robert Fowler ${ }^{1}$, Jeremy E. Niven ${ }^{1}$, James D. Gilbert ${ }^{1,2}$ and Dave Goulson ${ }^{1}$

$5 \quad{ }^{1}$ School of Life Sciences, University of Sussex, Falmer, UK

$6{ }^{2}$ School of Biological, Biomedical and Environmental Sciences, University of Hull, Hull, UK

7

8 Corresponding Author:

9 Elizabeth Nicholls

10 Email Address: e.nicholls@sussex.ac.uk

11

12

13

14

15

16

17

18

19

20

21

22

23

24

25

26

27

28

29 


\section{Abstract}

There is widespread concern regarding the effects of agro-chemical exposure on bee health, of which neonicotinoids, systemic insecticides detected in the pollen and nectar of both crops and wildflowers, have been the most strongly debated. The majority of studies examining the effect of neonicotinoids on bees have focussed on social species, namely honey bees and bumble bees. However, most bee species are solitary, their life histories differing considerably from these social species, and thus it is possible that their susceptibility to pesticides may be quite different. Studies that have included solitary bees have produced mixed results regarding the impact of neonicotinoid exposure on survival and reproductive success. While the majority of studies have focused on the effects of adult exposure, bees are also likely to be exposed as larvae via the consumption of contaminated pollen. Here we examined the effect of exposure of Osmia bicornis larvae to a range of field-realistic concentrations $(0-10 \mathrm{ppb})$ of the neonicotinoid clothianidin, observing no effect on larval development time, overwintering survival or adult weight. Flow-through respirometry was used to test for latent effects of larval exposure on adult physiological function. We observed differences between male and female bees in the propensity to engage in discontinuous gas exchange, however no effect of larval clothianidin exposure was observed. Our results suggest that previously reported adverse effects of neonicotinoids on $O$. bicornis are most likely mediated by impacts on adults.

\section{Introduction}

Bees are important pollinators of crops and wild flowers, therefore ongoing population declines and extinctions are a major cause for concern, particularly considering increasing global reliance on insect-pollinated crops (Holden, 2006; Gross, 2008; Aizen \& Harder, 2009). Such declines are likely attributable to a number of factors, including habitat loss, the spread of non-native species, emergent pathogens and perhaps most controversially, exposure to pesticides (Goulson, Lye, \& Darvill, 2008; Goulson, Nicholls, Botías, \& Rotheray, 2015; Ollerton, Erenler, Edwards, \& Crockett, 2014; Vanbergen, 2013). Of the multitude of chemicals applied to arable land, 
61 neonicotinoids are some of the most widely used insecticides (Jeschke et al., 2011; Simon-Delso 62 et al., 2014) and the class most strongly implicated in bee declines (Sanchez-Bayo \& Goka, 2014; Woodcock et al., 2016). Typically applied as a seed treatment to oilseed and cereal crops, these systemic insecticides become incorporated into all tissues of the plant as it grows, including pollen and nectar, providing a direct route of oral exposure for bees and other pollinators.

Neonicotinoids are neuro-active insecticides which target nicotinic acetylcholine (nACh) receptors in the insect nervous system, causing over-stimulation of nerve cells, paralysis and at sufficiently high doses, death (Tomizawa \& Casida, 2005; Palmer et al., 2013; Moffat et al., 2015). Laboratory studies have found the oral toxicity of neonicotinoids to be relatively high for bees (4-5 ng/honeybee, Suchail, Guez, \& Belzunces, 2001), and sub-lethal effects have also been observed following exposure to concentrations within the range detected in field-collected pollen and nectar (reviewed in Alkassab \& Kirchner, 2017). These effects include deficits in learning (Williamson \& Wright, 2013; Stanley et al., 2015), foraging (Feltham, Park \& Goulson, 2014; Gill \& Raine, 2014) and homing ability (Henry et al., 2012), all of which are essential to bee survival and reproduction.

While previous research has typically focussed on the effects of adult exposure to acute doses via contaminated nectar, the frequent detection of neonicotinoid residues in the pollen of both crops and wildflowers suggests that bees are likely to be exposed to neonicotinoids throughout their entire life cycle (Mullin et al., 2010; Dively et al., 2015; Botias et al. 2015; David et al., 2016; Ellis et al., 2017), and recent studies have shown that the severity of the effect can be dependent on both the timing and duration of exposure (Suchail, Guez \& Belzunces, 2001; Decourtye, Lacassie \& Pham-Delègue, 2003; Rortais et al., 2005; Rondeau et al., 2014; Heard et al., 2017). Though under-investigated at present, studies have shown that early exposure to neonicotinoids can negatively impact on larval development (Wu, Anelli \& Sheppard, 2011; Gregorc et al., 2012; Derecka et al., 2013; Rondeau et al., 2014; Rosa et al., 2016) and may also have latent effects on adult physiology and behaviour (Yang et al., 2012; Tomé et al., 2012; Tan et al., 2015; Peng \& Yang, 2016).

The limited body of research investigating the effects of chronic or developmental exposure to neonicotinoids may arise in part from a bias towards studying bees that are commercially reared for pollination, namely honey bees and bumble bees (Lundin et al., 2015), 
92 which are all social species. While the biology of these species is well understood, it can be 93 challenging to study the effects of larval exposure to pesticides independently of worker effects, or to monitor individuals over their entire lifetime. Assessing effects on reproduction in these social species is also complicated given that the unit of replication is the colony. Moreover, it remains unclear whether these managed species actually serve as a good proxy for the diversity of bee species that likely come into contact with pesticides when foraging and nesting in arable landscapes (Devillers et al., 2003; Scott-dupree, Conroy \& Harris, 2009; Biddinger et al., 2013; Rondeau et al., 2014; Arena \& Sgolastra, 2014; Heard et al., 2017). The majority of wild bees are solitary and, consequently, have life histories that differ considerably from those of managed pollinators. Flight periods and foraging preferences are highly variable between species and so the degree of exposure to pesticides is also likely to differ. Add to this inherent differences in physiology among species, including between honey bees and bumble bees (Cresswell et al., 2012; Piiroinen \& Goulson, 2016), and it becomes clear that much more research is needed to determine the sensitivity of wild bees to neonicotinoid exposure, as well as the implications of both larval and chronic exposure on bee development, adult functioning and ultimately, the stability of bee populations.

Here we investigate the effects of chronic, developmental exposure to a neonicotinoid in a solitary, cavity nesting bee, Osmia bicornis. A pollen generalist, the flight period of $O$. bicornis overlaps considerably with that of winter-sown oilseed rape, and studies have shown that $O$. bicornis can greatly benefit from this mass-flowering crop in terms of reproductive output (Jauker et al., 2012; Holzschuh et al., 2013; Diekötter et al., 2014). However, concerns have been raised regarding the trade-off between increased food availability and exposure to pesticides such as neonicotinoids (Rundlöf et al., 2015). The small number of studies of neonicotinoid exposure in this species have so far yielded mixed results regarding their sensitivity. A large-scale field experiment by Rundlöf et al. (2015) found a severe effect of proximity to clothianidin-treated spring-sown oilseed rape on O.bicornis nesting success, as well as wild bee density more generally. A laboratory-based study by Sandrock et al. (2014) found that adult $O$. bicornis exposed to nectar containing a combination of thiamethoxam (2.87 ppb) and clothianidin $(0.45 \mathrm{ppb})$ also had reduced reproductive success. In contrast, Peters et al. (2016) found little effect of proximity to winter-sown, clothanidin-treated oilseed rape on $O$. bicornis reproduction. Levels of clothianidin in pollen sampled from nests close to treated 
123 oilseed rape were found to be low (1-1.7 ppb), with the majority of pollen samples containing

124 residues below the limit of quantification (LOQ), though it should be noted that pollen was 125 sampled at a single time point during the flowering season (23 days after cocoon placement and 126 the start of oilseed rape full flowering) and pooled across nests, therefore individual larva 127 developing in nest cells provisioned earlier or later in the season may have experienced differing 128 levels of exposure. None of the aforementioned studies directly examined the effect of

129

130

131

132

133

134

135

136

137

138

139

140

141

142

143

144

145

146

147

148

149

150

151

152

153 neonicotinoid exposure on $O$. bicornis larval development.

Female $O$. bicornis, like many other species of cavity nesting bee, provision their offspring with a single mass of unprocessed pollen, providing an opportunity to manipulate and tightly control pesticide exposure throughout development without the confound of adult or worker exposure (Abbott et al., 2008; Konrad et al., 2008; Hodgson, Pitts-Singer \& Barbour, 2011). In this study, we spiked pollen with a range of clothianidin concentrations $(0-10 \mathrm{ppb})$ representative of the levels detected in the pollen of both oilseed rape (Mean $=2.27 \mathrm{ppb}$, Range $=\leq 0.12-14.5$ ppb, Botías et al. 2015) and field margin plants likely to be visited by O. bicornis (Range=1.19.4 ppb, Krupke et al., 2012; Mean = 1.2 ppb, Range= 0-5.9 ppb, Rundlöf et al., 2015; Range $\leq 0.12-0.36 \mathrm{ppb}$, Botías et al., 2015) and monitored effects on larval development time, survival and overwintering success. Because larval exposure to neuro-toxic compounds may affect nervous system development and basic autonomic functioning (Dwyer, McQuown \& Leslie, 2009; Peng \& Yang, 2016), we also tested for latent effects of larval exposure on adult physiology. Cellular metabolism which underpins all physiological processes, is reliant on the delivery of oxygen to tissues and the removal of carbon dioxide, which in insects occurs via the tracheal system. The rate of gas exchange is mediated by the opening and closing of the spiracles, which is under neuronal control. Many insects exhibit cyclical or discontinuous patterns of gas exchange, where spiracles are kept closed for prolonged periods, hypothesised to be a strategy to minimise water loss when resting (Buck, 1953; 1955; Quinlan \& Hadley, 1993; Quinlan \& Lighton, 1999). Exposure to neuro-active pesticides has been show to affect patterns of gas exchange, as well as the propensity to engage in discontinuous gas exchange across a diversity of insects (reviewed in Karise \& Mänd, 2015). In bees, acute exposure to imidacloprid has been shown to alter abdominal ventilation patterns in adult honey bees (Hatjina et al., 2013) and to increase metabolic rates in the stingless bee Melipona quadrifasciata (Tomé et al., 2015). Therefore patterns of respiratory gas exchange are considered a useful physiological measure of 
154 an insects' response to stress, and so we used flow-through respirometry to examine the 155 metabolic rate and respirometry rhythms of adult $O$. bicornis exposed to clothianidin as larvae.

156

157

158

159

160

161

162

163

164

165

166

167

168

169

170

171

172

173

174

175

176

177

178

179

180

181

182 183

\section{Methods}

\subsection{Study organism}

Osmia bicornis (Linneaus, 1758) is a solitary bee that nests in dead plant stems. Adults emerge in early spring, whenever temperatures exceed $c a .12^{\circ} \mathrm{C}$. Following mating, females begin provisioning nests with pollen and nectar (hereafter referred to as pollen provision), and once a sufficiently large provision of pollen has been collected, an egg is laid and then a mud partition is built to form an individual nest cell (Raw, 1972). The female then begins provisioning another cell, and so on, until the tube is full, at which point the female seals the entrance with mud. Within a nest tube, female eggs tend to be laid first, and provisioned with more pollen, with male eggs and their smaller provisions found towards the entrance of the nest. Approximately one week after laying, eggs hatch and the larvae begin to eat the pollen provision. Once all the pollen is consumed (after $c a$. 30 days) the larvae spin a cocoon and pupate, overwintering as an adult inside the cocoon and emerging the following spring (Raw, 1972).

\subsection{Rearing methods}

Six 'trap nests', consisting of cardboard tubes (8 $\mathrm{mm}$ diameter, $150 \mathrm{~mm}$ in length) housed in a waterproof shelter, were positioned a few metres above ground in an orchard at Stanmer Organics, East Sussex, UK. Stanmer Organics has been Soil Association certified organic for the past 10 years. Nests were placed out in early April 2016, and each contained a release tube seeded with 12 female and 10 male cocoons. Cocoons were checked for viability prior to release by making a small incision at the tip of the cocoon, and clypeal hair colour was used to distinguish between male and female bees. From mid-May onwards, once bees had emerged and females had begun provisioning the nests, tubes were checked daily for the presence of eggs. Eggs plus pollen provisions were removed from the nests and added to individual polystyrene nest blocks, which had Perspex lids to permit observation of larval development. A small piece of cotton wool was used to plug the entrance to the nests, and nests were covered when in the field, to limit light exposure. 
Nest blocks were then returned to the laboratory and pollen provision (plus egg) were

185

186

187

188

189

190

191

192

193

194

195

196

197

198

199

200

201

202

203

204

205

206

207

208

209

210

211

212

213 weighed to the nearest 0.001g (Precisa 125A, Newport Pagnell, Bucks, UK) before being placed into a dark incubator $\left(20^{\circ} \mathrm{C}, 75 \% \mathrm{RH}\right)$. Bees were assigned to one of four treatments; $0 \mathrm{ppb}$ (control), 1ppb, 3ppb or 10ppb clothianidin, with care taken to balance the provision weight and nest position (as a proxy for sex) across treatments.

\subsection{Pesticide Exposure}

Clothianidin is currently the most commonly used seed treatment worldwide, and is a breakdown product of another commonly applied neonicotinoid, thiamethoxam (Simon-Delso et al. 2015). Data on neonicotinoid residue levels commonly present in the nests of $O$. bicornis was unfortunately lacking at the time of the experiment (but see Peters et al. 2017 which detected concentrations of 1-1.7 ppb clothianidin in O. bicornis pollen provisions) so we selected a range of clothianidin doses $(0-10 \mathrm{ppb})$ to reflect the range of concentrations commonly detected in field-collected oilseed rape and wildflower pollen (Botias et al. 2015; Rundlöf et al. 2015; Krupke et al. 2012), with $10 \mathrm{ppb}$ serving as a 'worst-case scenario' level of exposure, though still within the range of concentrations detected in the pollen of crops and wildflowers. To contaminate pollen provisions, $10 \mathrm{mg}$ of technical grade clothianidin (Sigma-Aldrich, Gillingham, UK) was diluted in $10 \mathrm{ml}$ of acetone to give an initial $1 \mathrm{mg} / \mathrm{ml}$ stock, which was then further diluted with acetone to produce a stock of $0.01 \mathrm{mg} / \mathrm{ml}$, both of which were stored at $-80^{\circ} \mathrm{C}$. On the day of pollen collection, $0.01 \mathrm{mg} / \mathrm{ml}$ stock was diluted with a mixture of acetone and water $(10 \%$ acetone $\mathrm{v} / \mathrm{v})$ to give a $100 \mathrm{ng} / \mathrm{ml}$ solution, which was used to contaminate provisions in the $10 \mathrm{ppb}$ treatment. This stock was further diluted to $30 \mathrm{ng} / \mathrm{ml}$ and $10 \mathrm{ng} / \mathrm{ml}$ to contaminate pollen in the 3 and $1 \mathrm{ppb}$ treatments, respectively. Approximately $50 \mu \mathrm{L}$ of solution was injected into a longitudinal fissure made in each pollen provision, with the exact volume varied according to provision weight to standardise the concentration within treatments. Pollen provisions in the 0 ppb group were injected with acetone and water alone. To test the accuracy of the spiking method and degradation of the compounds over time, a sub-sample of pollen from each treatment was frozen for residue analysis at $-80^{\circ} \mathrm{C}$, either after 24 hours or 28 days of incubation. Pollen samples were extracted using the QuEChERS method and analysed for neonicotinoid residues using ultra high-performance liquid chromatography tandem mass spectrometry 
214 (UHPLC-MS/MS) as described in Botias et al. (2015). Samples were screened not only for 215 clothianidin, but also for four other commonly applied neonicotinoids: thiamethoxam, 216 imidacloprid, acetamiprid and thiacloprid (see Table S1 for method detection limits, 217 quantification limits, absolute recoveries).

218

219

\subsection{Monitoring development}

220

Following contamination of pollen provisions, nest blocks were returned to the incubator and

221

222

223

224

225

226

227

228

229

230

231

232

233

234

235

236

237

238

239

240

241

242

243

checked daily for the following developmental stages: Egg hatching, defecation, total pollen consumption, initiation of cocoon spinning, and cocoon completion. Larvae were reweighed once all pollen had been consumed, and the efficiency of food conversion was calculated as the difference between the body weight of the mature larvae and the fresh pollen provision. Cocoons were weighed ten days after completion (once fully darkened) to give an estimate of pre-pupal weight. One hundred and twenty days after the beginning of the neonicotinoid exposure, the temperature in the incubator was reduced to $14^{\circ} \mathrm{C}$. Three weeks later, all nest blocks were moved to a cool climate controlled chamber held at $4^{\circ} \mathrm{C}$ and $50 \%$ relative humidity $(\mathrm{RH})$. Following a 196 day overwintering period, bees inside their cocoons were placed back into an incubator, warmed to $20^{\circ} \mathrm{C}$ and checked daily for emergence.

\subsection{Metabolic rate measurement}

Metabolic rate was measured for each bee on the day of emergence using flow-through respirometry, using $\mathrm{CO}_{2}$ production as the measure of metabolic rate. Atmospheric air was scrubbed of $\mathrm{CO}_{2}$ and $\mathrm{H}_{2} \mathrm{O}$ using a Drierite ${ }^{\circledR}$-Ascarite ${ }^{\circledR}$ column, before being pumped through two chambers of identical volume $(2 \mathrm{ml})$, one of which was used for measuring $\mathrm{CO}_{2}$ production, the other to serve as a reference. Flow rate through the chambers was maintained at 150 $\mathrm{ml} /$ minute via two mass flow controllers (GFC17; Aalborg, NY, USA). After passing through the chambers, air flowed into two separate channels of an infrared $\mathrm{CO}_{2}-\mathrm{H}_{2} \mathrm{O}$ analyser (Li-7000; LiCor, Lincoln, NE, USA), and the output signal from the two analysers was captured by LiCor software. The sampling rate was $5 \mathrm{~Hz}$. The temperature in the room was held at $21^{\circ} \mathrm{C}$ (Mean \pm $\mathrm{SD}=20.82 \pm 2.11^{\circ} \mathrm{C}$ ) and measurements lasted for 30 minutes per bee. This included an initial period of $\mathrm{CO}_{2}$ stabilisation after opening and closing the chamber, and time for bees to recover 
244 from being transferred. Once the bee was secured inside the chamber the experimenter left the 245 room to minimise disturbance. We observed no changes in bee activity whilst in the chambers 246 during pilot studies (data not shown). Indeed, bees remained stationary throughout the recording 247 period. Following metabolic rate measurements, bees were removed from the chamber and 248 immediately weighed to the nearest $0.001 \mathrm{~g}$ (Precisa 125A, Newport Pagnell, Bucks, UK).

249

250

251

252

253

254

255

256

257

258

259

260

261

262

263

264

265

266

267

268

269

270

271

272

273

274

275

Respirometry data was analysed using OriginPro 2016 software (Origin Lab, Northampton, MA, USA). Volumes of $\mathrm{CO}_{2}(\mathrm{ppm})$ were baseline corrected and temperature normalised using the Q10 correction for temperature differences (Morgan et al. 1985). To calculate the rate of $\mathrm{CO}_{2}$ production per bee, volume $\mathrm{CO}_{2}(\mathrm{ppm})$ was converted to $\mathrm{CO}_{2}$ fraction and then multiplied by the flow rate $\left(200 \mathrm{ml} \mathrm{min}^{-1}\right)$. The integral of $\mathrm{CO}_{2} \mathrm{~min}^{-1}$ vs. min was calculated for a stable period of the recording, totalling approximately 20 minutes per bee. This value was then divided by the exact measurement time for each bee $(c a .0 .33 \mathrm{~h})$ to give a rate of $\mathrm{ml} \mathrm{CO} \mathrm{CH}^{-1}$. Patterns of $\mathrm{CO}_{2}$ production over time were visually inspected for each bee and categorised as either continuous, discontinuous or cyclic, though no observations of cyclic gas exchange were observed (Buck, 1958; Lighton, 1996; Chown et al. 2006; Kovac et al. 2007).

\subsection{Statistical Analysis}

All statistical analyses were conducted using SPSS v.22. Normality was assessed via inspection of q-q plots combined with the Shapiro-Wilk statistic. Homogeneity of variance was assessed via Levene's test. Where necessary data were transformed to meet the assumptions of parametric tests, or non-parametric alternatives were used. Fisher's exact test was used to compare mortality (number of dead vs. live bees) across clothianidin treatments during larval, pupal and overwintering stages of development. Pollen provision weight was log-transformed and compared across treatments using analysis of variance (ANOVA). There was no correlation between pollen provision weight and the time to cocoon spinning, so ANOVA was used to compare larval development time. Time to adult emergence was analysed using a two-way ANOVA with treatment and sex as the predictors. Larval and adult body mass was compared between treatments using analysis of co-variance (ANCOVA), with log-transformed pollen provision weight included as the co-variate. Given that provision weight is highly dependent on sex, the analysis was run separately for male and female bees. Homogeneity of regression slopes 
276 was assessed by testing for an interaction between provision weight and the categorical predictor,

277 treatment (in all cases $\mathrm{p}>0.05$ ). Weight loss over winter was compared using a mixed-design

278 ANOVA, with body mass (pre-pupa $v s$. adult) as the within-subjects measure and treatment and

279 sex as the between-subjects predictors. Metabolic rate data was log-transformed and analysed

280 using an ANCOVA, with neonicotinoid treatment and gas exchange pattern (discontinuous vs.

281 continuous) as the predictors and log-transformed adult body mass as the co-variate. Again,

282 because adult body mass differs between the sexes, the analysis was run separately for male and

283 female bees.

284

285 3. Results

286 3.1 Residue Analysis

287 Control (0 ppb) pollen provisions contained no neonicotinoid residues, and no neonicotinoids 288 other than clothianidin were detected in samples from each of the treatment groups, confirming 289 that pollen collected by females at the field site was free of neonicotinoids (Table 1). 290 Comparison of pollen provisions that were frozen for residue analysis after either 24 hours or 28 291 days of incubation showed little evidence of degradation during this time, meaning bees were 292 exposed to neonicotinoids throughout larval development (Wilcoxon Signed-Rank test, 24 hours vs. 28 days; 1 ppb, $Z=0.000, p=1.000 ; 3$ ppb, $Z=-0.535, p=0.593 ; 10$ ppb, $Z=-0.535, p=0.593)$.

294

295

\subsection{Mortality}

296 Of the 161 eggs collected, 25 were excluded from analysis either due to mechanical damage 297 $(n=9)$, mould $(n=7)$ or the presence of parasites $(n=9)$. At each developmental stage, a maximum of 4 bees died per treatment (Table 2) and there was no significant difference in mortality between treatment groups during larval development $\left(\chi^{2}=0.837, \mathrm{df}=3, \mathrm{p}=0.882\right)$, pupation $\left(\chi^{2}=\right.$ 4.351, $\mathrm{df}=3, \mathrm{p}=0.214)$ adult overwintering $\left(\mathrm{x}^{2}=2.212, \mathrm{df}=3 \mathrm{p}=0.605\right)$, or across all stages of development combined $\left(\chi^{2}=1.718, \mathrm{df}=3, \mathrm{p}=0.652\right)$. 
304 Larval development time, defined as the number of days from egg hatching to the initiation of 305 cocoon spinning, did not differ between treatments (Table 2; ANOVA, $\mathrm{F}_{3,115}=0.526, \mathrm{p}=0.665$ ). 306 Bees took between 21 and 42 days to develop, with a mean of 30-32 days across all treatment 307 groups (Mean $\pm \mathrm{SD}$; Control $=31 \pm 5 ; 1 \mathrm{ppb}=31 \pm 4 ; 3 \mathrm{ppb}=30 \pm 4 ; 10 \mathrm{ppb}=32 \pm 4$ )

308

309

310

311

312

313

314

315

316

317

318

319

320

321

322

323

324

325

326

327

328

329

330

331

332

333

\subsection{Larval food conversion and over-winter weight loss}

Initial pollen provision weight did not differ between treatments (Table S2, ANOVA, $\left.\mathrm{F}_{3,133}=0.053, \mathrm{p}=0.984\right)$. As might be expected, provision weight had a strong effect on resulting larval body mass (ANCOVA, Pollen Weight (co-variate), $\mathrm{F}_{1,116}=258.941, \mathrm{p}>0.001$ ), but there was no difference in larval mass between clothianidin treatments (Figure 1; ANCOVA, Treatment, $\left.F_{3,101}=0.722, p=0.541\right)$ suggesting that exposure had no effect on the ability of bees to convert pollen into wet body mass. Overall, female larvae had a higher body mass than males (Mann-Whitney, $\mathrm{U}=145, \mathrm{Z}=-8.329, \mathrm{p}<0.001 ;$ Median \pm SD Female $=334.50 \pm 57.24 \mathrm{mg}$; Male $=225.8$ $\pm 30.12 \mathrm{mg})$,

Following overwintering, cocoons were placed back into an incubator at $20^{\circ} \mathrm{C}$ and checked daily for emergence. As in the wild, males emerged first (ANOVA, Sex, $\mathrm{F}_{1,103}=$ 169.099, $\mathrm{p}<0.001$ ), between 0-14 days after warming (Mean $\pm \mathrm{SD}=6 \pm 4$ days), and females emerged after 6-26 days (Mean $\pm \mathrm{SD}=16 \pm 3$ days). There was no effect of clothianidin treatment on emergence time (Table S3; ANOVA, Treatment, $\mathrm{F}_{3,103}=0.095, \mathrm{p}=0.963$ ).

Adult body mass did not differ between treatments (Figure 2A; ANCOVA, Treatment, Female $\mathrm{F}_{3,50}=1.830, \mathrm{p}=0.154$; Males, $\mathrm{F}_{3,49}=0.769, \mathrm{p}=0.517$ ), nor did the amount of weight lost over winter (Figure 2B; Mixed ANOVA, Time x Treatment, $\mathrm{F}_{3,95}=0.750, \mathrm{p}=0.525$ ). In absolute terms, female bees lost more weight than males (Mixed ANOVA, Time x Sex, $\mathrm{F}_{1,95}=34.637$, $\mathrm{p}<0.001$; Mean $\pm \mathrm{SD}$, Females $=47.64 \pm 11.38 \mathrm{mg}$, Males $=36.80 \pm 6.49 \mathrm{mg}$ ), but as a percentage of pupal weight, weight loss was similar between the sexes (Mean $\pm \mathrm{SD}$, Females $=36.04 \pm 5.54$ $\%$; Males $=39.90 \pm 4.98 \%$ ).

\subsection{Metabolic rates}

Previous studies have shown that pesticide exposure can alter gas exchange patterns in insects as well as the propensity to engage in discontinuous gas exchange (see Karise \& Mand, 2015 for 
334 review). Therefore, the proportion of bees engaging in continuous (CGE, Fig. 3A) versus

335 discontinuous (DGE, Fig. 3B) gas exchange was compared across clothianidin treatments using a 336 3-way loglinear analysis (Factors: Breathing Pattern, Sex, Treatment). This produced a final 337 model which retained only the Breathing Pattern x Sex interaction (Likelihood ratio $\chi^{2}=6.686$, $338 \mathrm{df}=12, \mathrm{p}=0.878$ ), indicating that there was no significant difference between treatments in the 339 propensity to engage in CGE but that overall, female bees were 2.7 times more likely to perform 340 CGE than males (Table S4, Breathing Pattern $x$ Sex, $\chi^{2}=4.149, \mathrm{df}=1, \mathrm{p}=0.042$ ).

341 There was no significant interaction between breathing pattern and body mass for either 342 sex, indicating a similar mass-scaling of metabolic rate between bees engaged in CGE versus 343 DGE (Fig. 3C, Table 3; ANCOVA, Breathing Pattern x Log-body mass, Females: $F_{1,49}=2.054$, $344 \mathrm{p}=0.158$; Males: $\mathrm{F}_{1,44}=0.887, \mathrm{p}=0.351$ ), though bees engaged in CGE had a significantly higher 345 metabolic rate (Table 3; ANCOVA, Breathing Pattern, Females: $F_{1,50}=215.839$, p $<0.001$; Males: $\left.346 \mathrm{~F}_{1,45}=72.212, \mathrm{p}<0.001\right)$. For both sexes there was no significant difference in metabolic rate 347 between clothiandin treatments (Figure 4, ANCOVA, Treatment, Females: $F_{3,47}=1.767, p=0.166$; 348 Males: $\left.\mathrm{F}_{3,42}=0.819, \mathrm{p}=0.491\right)$.

\section{Discussion}

352

Concerns have been raised regarding the impact that exposure to pesticides such as neonicotinoids have on bee health and non-target organisms more generally (Pisa et al., 2014). Until recently, the majority of studies and regulatory tests have focussed on the effects of short term, acute exposure in adult bees, with a bias towards commercially reared social species such as honeybees and bumblebees. Given that neonicotinoid pesticides have been detected in the pollen and nectar not only of treated crops but also flowering wild plants growing in field margins and ornamental garden plants (Botías et al., 2015; Mogren \& Lundgren, 2016; David et al., 2016; Long \& Krupke, 2016) a host of bee species are likely to encounter these chemicals when foraging (Hladik, Vandever \& Smalling, 2016; Botías et al., 2017), yet we know relatively little about the sensitivity of wild bees to neonicotinoids.

Here we examined the effect of chronic, larval exposure to neonicotinoids on the 363 development and survival of a solitary bee, Osmia bicornis, under controlled laboratory 364 conditions. We found that exposure to clothianidin at doses representative of the concentrations 
365 detected in field-collected pollen and nectar had no effect on development time or the efficiency 366 with which larvae converted pollen into wet body mass. Overall, developmental mortality was 367 similar between treatment groups ( $c a$. 20\%). A higher proportion of control group pupae failed to 368 eclose, which elevated the overall mortality of this group above that of the treatment groups (ca. $36930 \%$ in total). Once cocoons were placed back into a warmed incubator the following spring, 370 there was no difference between treatment groups in the time to emerge, and adult body weight 371 did not differ between exposed and non-exposed bees. Overall, our findings suggest that larvae 372 of $O$. bicornis are insensitive to clothianidin exposure up to concentrations of $10 \mathrm{ppb}$.

373 A study of a North American bee of the same genus (Osmia lignaria), using a similar 374 method of pollen contamination as our study, found that while the timing of discrete larval 375 development stages was marginally affected by imidacloprid exposure, this effect was only 376 apparent above $30 \mathrm{ppb}$. Indeed, even at $300 \mathrm{ppb}$, a concentration several orders of magnitude 377 higher than that routinely detected in the field, no differences in survival to adulthood or adult 378 body weight were observed (Abbott et al., 2008). In the same study, no effect of clothianidin 379 exposure (3-300 ppb) on another species of megachilid bee, Megachile rotunda, was observed. 380 Abbott et al. (2008) reared O. lignaria both in the laboratory and outdoors and no differences were observed in survival, though bees reared indoors did develop more quickly. Our study was conducted entirely in the laboratory to permit tight control over pesticide exposure and the rearing environment. Larvae were reared at a constant temperature of $20^{\circ} \mathrm{C}$, based on previous findings regarding optimal temperatures for normal O. bicornis development (Radmacher \& Strohm, 2011). It remains to be tested whether fluctuating temperatures and varying humidity experienced under natural conditions would disproportionately affect clothianidin-exposed $O$. bicornis relative to non-exposed bees, though this seems unlikely given that development times did not differ from those reported for bees reared outdoors (Raw, 1972; Radmacher \& Strohm, 389 2011).

Evidence from honeybees suggests that larval exposure to neonicotinoids can lead to physiological and behavioural changes in adult bees, though the mechanism(s) underpinning this are still not well understood (Yang et al., 2012; Peng \& Yang, 2016). As a result, we were also interested in whether larval exposure to clothianidin leads to latent effects in adult bees. Because changes in the function of nervous tissue can affect basic autonomic processes such as 
396 \& Brunet, 2012; Hatjina et al., 2013; Karise \& Mänd, 2015), we measured the metabolic rates of

397

398

399

400

401

402

403

404

405

406

407

408

409

410

411

412

413

414

415

416

417

418

419

420

421

422

423

424

425

426 adult bees on the day of emergence. Relatively little is known about the effects of developmental pesticide exposure on adult insect metabolic rates, but acute exposure has been found to alter respiratory rhythms, particularly the propensity to engage in discontinuous gas exchange (Zafeiridou \& Theophilidis, 2004; Hatjina et al., 2013; Tomé et al., 2015). We found that while the majority of bees engaged in discontinuous patterns of $\mathrm{CO}_{2}$ release, a small proportion of bees breathed continuously throughout the observation period, but this propensity was not affected by clothianidin exposure. It also did not appear to reflect differences in activity within the recording chambers. Interestingly, female bees were almost three times more likely to engage in continuous gas exchange than males. The factors underlying switches between continuous and discontinuous patterns of gas exchange in insects are still widely debated (e.g. Contreras \& Bradley, 2009), and so the reason why female bees were less likely to engage in discontinuous gas exchange is not clear, though could be related to sex-specific differences in body mass causing females to produce more $\mathrm{CO}_{2}$ at rest (Terblanche et al., 2008).

The scaling of metabolic rate was identical across bees engaged in continuous versus discontinuous gas exchange, though metabolic rates were higher for bees exchanging $\mathrm{CO}_{2}$ continuously. When metabolic rates were compared across treatments, we observed no significant treatment effect, though bees exposed to $3 \mathrm{ppb}$ and $10 \mathrm{ppb}$ clothianidin did have lower metabolic rates, on average. This suggests that the respiratory system of Osmia bicornis is unaffected by larval clothianidin exposure, though it remains to be tested whether other physiological or behavioural processes are affected. To our knowledge, the current study is the first to measure metabolic rates in O. bicornis. Previous studies have used flow-through respirometry to measure oxygen consumption at various stages throughout the life cycle of the cavity nesting bees, $O$. lignaria and Megachile rotunda, utilising the rate of oxygen consumption as a proxy for diapause intensity (Kemp, Bosch \& Dennis, 2004; Sgolastra et al., 2010, 2011; Yocum et al., 2011). Scaling relationships were not reported in these studies, therefore ours is the first to describe the intraspecific scaling of metabolic rate with body mass in a Megachilid bee, a measure which can be extremely useful in understanding the physiological functioning of an organism, as well as resistance to stress (Burton et al., 2011).

Our results contrast with previous observations of adverse effects of adult neonicotinoid exposure in this species (Sandrock et al., 2014a; Rundlöf et al., 2015). Comparative studies have 
427 found adult $O$. bicornis to be more sensitive to clothianidin-spiked nectar than either honeybees

428 (Heard et al., 2017) or honeybees and bumblebees (Sgolastra et al., 2016) though effects became 429 apparent over different time-scales. A study of the closely related $O$. cornuta revealed that acute 430 exposure to clothianidin can impair navigational behaviour under laboratory conditions (Jin et 431 al., 2015). Sandrock et al. (2014) provided caged adult bees with sucrose solution spiked with 432 thiamethoxam and clothainidin and found that females produced fewer nests, with fewer brood 433 cells than those completed by female bees provided with uncontaminated sucrose solution. 434 Larval and overwintering mortality was found to be higher in the offspring of neonicotinoidexposed bees, such that fewer adult bees, and proportionally more males, emerged the following spring. However, as in our study, offspring body size did not differ between control and neonicotinoid-exposed bees. Because pollen provisions in Sandrock et al.'s study were not found to contain neonicotinoids, the levels that larvae themselves were exposed to during development is not clear. Indeed, it may be that the reduction in offspring emergence is more attributable to effects on adult bee physiology or behaviour than to effects on the larvae. For example, consuming contaminated nectar may have impaired adults' provisioning ability (Feltham, Park \& Goulson, 2015; Gill \& Raine, 2014; Stanley \& Raine, 2016), sex allocation (Whitehorn et al. 2015) or the viability of gametes (Straub et al. 2016), as has been observed in other bee and wasp species.

Though there are clear methodological differences between previous studies of adult exposure to neonicotinoids and that presented here, both in terms of experimental design and the particular neonicotinoid and/or concentration used, our results tentatively suggest that the effects of neonicotinoid exposure may be less severe for O. bicornis larvae than for adults. Certainly in honeybees it has been suggested that larvae may be more tolerant to neonicotinoids than adult bees (Yang et al., 2012), which has been proposed to arise from differential nACh-receptor expression across developmental stages (Thany et al., 2003; Thany \& Gauthier, 2005).

452 Additionally, certain higher-level structures targeted by neonicotinoids, such as the mushroom bodies, are not fully developed in bee larvae (Farris et al., 1999). The latent effects of larval exposure to neonicotinoids on adult cognitive ability remain to be tested in O. bicornis.

Our findings contribute to an accumulating body of evidence showing that the impacts of neonicotinoid exposure can be both species specific and dependent on developmental stage, and serve as a caution against evaluating the toxicity of a particular pesticide based on the findings 
458 from a single 'model' species such as honeybees or bumblebees. In this study we considered the

459 impact of a single pesticide in isolation, but in reality it is likely that bees are exposed to a suite 460 of agrochemicals via the pollen and nectar they collect (David et al., 2016; Botías et al., 2017; ,

461 with synergistic effects of combined exposure to neonicotinoids and fungicides having already

462 been observed in adults of $O$. bicornis and the related $O$. cornifrons (Biddinger et al., 2013;

463 Sgolastra et al., 2016). Therefore more data are needed to quantify the exposure risk of wild bees

464 foraging and nesting in arable landscapes and the contribution of such stressors to ongoing bee 465 population declines.

466

467

468

469

470

471

472

473

474

475

476

477

478

479

480

481

482

483

484

485

486

487

488

489

490

491

492

493

494

495

\section{Acknowledgements}

The authors wish to thank Arthur David for screening pollen samples for neonicotinoid residues.

We would also like to thank Professor Erhard Strohm and Chris Whittles for advice on rearing bees, Thomas David and Douglas Morrison for assistance with developmental observations, and two anonymous referees for their comments on an earlier version of the manuscript.

\section{References}

Abbott VA., Nadeau JL., Higo HA., Winston ML. 2008. Lethal and sublethal effects of imidacloprid on Osmia lignaria and clothianidin on Megachile rotundata (Hymenoptera: Megachilidae). Journal of Economic Entomology 101:784-796. DOI: 10.1603/00220493(2008)101[784:LASEOI]2.0.CO;2.

Aizen MA., Harder LD. 2009. The global stock of domesticated honey bees is growing slower than agricultural demand for pollination. Current Biology 19:915-918. DOI: 10.1016/j.cub.2009.03.071.

Alkassab AT., Kirchner WH. 2017. Sublethal exposure to neonicotinoids and related side effects on insect pollinators: honeybees, bumblebees, and solitary bees. Journal of Plant Diseases and Protection 124:1-30. DOI: 10.1007/s41348-016-0041-0.

Arena M., Sgolastra F. 2014. A meta-analysis comparing the sensitivity of bees to pesticides. Ecotoxicology 23:324-334. DOI: 10.1007/s10646-014-1190-1.

Belzunces LP., Tchamitchian S., Brunet J-L. 2012. Neural effects of insecticides in the honey bee. Apidologie 43:348-370. DOI: 10.1007/s13592-012-0134-0.

Biddinger DJ., Robertson JL., Mullin C., Frazier J., Ashcraft S a., Rajotte EG., Joshi NK., Vaughn M. 2013. Comparative Toxicities and Synergism of Apple Orchard Pesticides to Apis mellifera (L.) and Osmia cornifrons (Radoszkowski). PloS one 8:e72587-e72587. DOI: $10.1371 /$ journal.pone.0072587.

Botías C., David A., Hill EM., Goulson D. 2017. Quantifying exposure of wild bumblebees to mixtures of agrochemicals in agricultural and urban landscapes. Environmental Pollution 222:73-82. DOI: 10.1016/j.envpol.2017.01.001.

Botías C., David A., Horwood J., Abdul-Sada A., Nicholls E., Hill E., Goulson D. 2015. 
496

497

498

499

500

501

502

503

504

505

506

507

508

509

510

511

512

513

514

515

516

517

518

519

520

521

522

523

524

525

526

527

528

529

530

531

532

533

534

535

536

537

538

539

540

541

Neonicotinoid Residues in Wildflowers, a Potential Route of Chronic Exposure for Bees. Environmental science \& technology 49:12731-40. DOI: 10.1021/acs.est.5b03459.

Burton T., Killen SS., Armstrong JD., Metcalfe NB. 2011. What causes intraspecific variation in resting metabolic rate and what are its ecological consequences? Proceedings of the Royal Society B 278:3465-3473. DOI: 10.1098/rspb.2011.1778.

Contreras HL., Bradley TJ. 2009. Metabolic rate controls respiratory pattern in insects. Journal of Experimental Biology 212:424-428.

Cresswell JE., Page CJ., Uygun MB., Holmbergh M., Li Y., Wheeler JG., Laycock I., Pook CJ., de Ibarra NH., Smirnoff N., Tyler CR. 2012. Differential sensitivity of honey bees and bumble bees to a dietary insecticide (imidacloprid). Zoology 115:365-71. DOI: 10.1016/j.zool.2012.05.003.

David A., Botías C., Abdul-Sada A., Nicholls E., Rotheray EL., Hill EM., Goulson D. 2016. Widespread contamination of wildflower and bee-collected pollen with complex mixtures of neonicotinoids and fungicides commonly applied to crops. Environment International 88:169-178. DOI: 10.1016/j.envint.2015.12.011.

Decourtye A., Lacassie E., Pham-Delègue M-H. 2003. Learning performances of honeybees (Apis mellifera $\mathrm{L}$ ) are differentially affected by imidacloprid according to the season. Pest management science 59:269-78. DOI: 10.1002/ps.631.

Derecka K., Blythe MJ., Malla S., Genereux DP., Guffanti A., Pavan P., Moles A., Snart C., Ryder T., Ortori C a., Barrett D a., Schuster E., Stöger R. 2013. Transient exposure to low levels of insecticide affects metabolic networks of honeybee larvae. PloS one 8:e68191e68191. DOI: 10.1371/journal.pone.0068191.

Devillers J., Decourtye A., Budzinski H., Pham-Delègue MH., Cluzeau S., Maurin G. 2003. Comparative toxicity and hazards of pesticides to Apis and non- Apis bees. A chemometrical study. SAR and QSAR in Environmental Research 14:389-403. DOI: 10.1080/10629360310001623980.

Diekötter T., Peter F., Jauker B., Wolters V., Jauker F. 2014. Mass-flowering crops increase richness of cavity-nesting bees and wasps in modern agro-ecosystems. GCB Bioenergy 6:219-226. DOI: 10.1111/gcbb.12080.

Dively GP., Embrey MS., Kamel A., Hawthorne DJ., Pettis JS. 2015. Assessment of Chronic Sublethal Effects of Imidacloprid on Honey Bee Colony Health. PLOS ONE 10:e0118748. DOI: 10.1371/journal.pone.0118748.

Dwyer JB., McQuown SC., Leslie FM. 2009. The dynamic effects of nicotine on the developing brain. Pharmacology \& Therapeutics 122:125-139. DOI: 10.1016/j.pharmthera.2009.02.003.

Ellis C., Park KJ., Whitehorn P., David A., Goulson D. 2017. The Neonicotinoid Insecticide Thiacloprid Impacts upon Bumblebee Colony Development under Field Conditions. Environmental Science \& Technology 51:1727-1732. DOI: 10.1021/acs.est.6b04791.

Farris SM., Robinson GE., Davis RL., Fahrbach SE. 1999. Larval and pupal development of the mushroom bodies in the honey bee,Apis mellifera. The Journal of Comparative Neurology 414:97-113. DOI: 10.1002/(SICI)1096-9861(19991108)414:1<97::AID-CNE8>3.0.CO;2Q.

Feltham H., Park K., Goulson D. 2014. Field realistic doses of pesticide imidacloprid reduce bumblebee pollen foraging efficiency. Ecotoxicology (London, England) 23:317-323. DOI: 10.1007/s10646-014-1189-7.

Gill RJ., Raine NE. 2014. Chronic impairment of bumblebee natural foraging behaviour induced 
542

by sublethal pesticide exposure. Functional Ecology:1459-1471. DOI: 10.1111/13652435.12292.

Goulson D., Lye GC., Darvill B. 2008. Decline and conservation of bumble bees. Annual review of entomology 53:191-208. DOI: 10.1146/annurev.ento.53.103106.093454.

Goulson D., Nicholls E., Botías C., Rotheray EL. 2015. Bee declines driven by combined stress from parasites, pesticides, and lack of flowers. Science 347:1255957. DOI: 10.1126/science. 1255957.

Gregorc A., Evans JD., Scharf M., Ellis JD. 2012. Gene expression in honey bee (Apis mellifera) larvae exposed to pesticides and Varroa mites (Varroa destructor). Journal of Insect Physiology 58:1042-1049. DOI: 10.1016/j.jinsphys.2012.03.015.

Gross M. 2008. Bee gloom deepens. Current Biology 18:1073. DOI: 10.1016/j.cub.2008.11.013. Hatjina F., Papaefthimiou C., Charistos L., Dogaroglu T., Bouga M., Emmanouil C., Arnold G. 2013. Sublethal doses of imidacloprid decreased size of hypopharyngeal glands and respiratory rhythm of honeybees in vivo. Apidologie 44:467-480. DOI: 10.1007/s13592013-0199-4.

Heard MS., Baas J., Dorne J- Lou., Lahive E., Robinson AG., Rortais A., Spurgeon DJ., Svendsen C., Hesketh H. 2017. Comparative toxicity of pesticides and environmental contaminants in bees: Are honey bees a useful proxy for wild bee species? Science of The Total Environment 578:357-365. DOI: 10.1016/j.scitotenv.2016.10.180.

Henry M., Béguin M., Requier F., Rollin O., Odoux J-F., Aupinel P., Aptel J., Tchamitchian S., Decourtye A. 2012. A common pesticide decreases foraging success and survival in honey bees. Science (New York, N.Y.) 336:348-350. DOI: 10.1126/science.1215039.

Hladik ML., Vandever M., Smalling KL. 2016. Exposure of native bees foraging in an agricultural landscape to current-use pesticides. Science of The Total Environment 542:469477. DOI: $10.1016 /$ j.scitotenv.2015.10.077.

Hodgson EW., Pitts-Singer TL., Barbour JD. 2011. Effects of the Insect Growth Regulator, Novaluron on Immature Alfalfa Leafcutting Bees, Megachile rotundata. Journal of Insect Science 11:1-10. DOI: 10.1673/031.011.0143.

Holden C. 2006. Report warns of looming pollination crisis in North America. Science (New York, N.Y.) 314:397. DOI: 10.1126/science.314.5798.397.

Holzschuh A., Dormann CF., Tscharntke T., Steffan-Dewenter I. 2013. Mass-flowering crops enhance wild bee abundance. Oecologia 172:477-484. DOI: 10.1007/s00442-012-2515-5.

Jauker F., Peter F., Wolters V., Diekötter T. 2012. Early reproductive benefits of mass-flowering crops to the solitary bee Osmia rufa outbalance post-flowering disadvantages. Basic and Applied Ecology 13:268-276. DOI: 10.1016/j.baae.2012.03.010.

Jeschke P., Nauen R., Schindler M., Elbert A. 2011. Overview of the status and global strategy for neonicotinoids. Journal of agricultural and food chemistry 59:2897-2908. DOI: $10.1021 /$ jf101303g.

Jin N., Klein S., Leimig F., Bischoff G., Menzel R. 2015. The neonicotinoid clothianidin interferes with navigation of the solitary bee Osmia cornuta in a laboratory test. Journal of Experimental Biology 218.

Karise R., Mänd M. 2015. Recent insights into sublethal effects of pesticides on insect respiratory physiology. Insect Physiology 5:31-39. DOI: 10.2147/OAIP.S68870.

Kemp WP., Bosch J., Dennis B. 2004. Oxygen consumption during the life cycles of the prepupa-wintering Bee Megachile rotundata and the adult-wintering Bee Osmia lignaria (Hymenoptera: Megachilidae). Annals of the Entomological Society of America 97:161- 
170. DOI: 10.1603/0013-8746(2004)097[0161:OCDTLC]2.0.CO;2.

Kestler P. 1991. Cyclic CO2 release as a physiological stress indicator in insects. Comparative Biochemistry and Physiology Part C: Comparative Pharmacology 100:207-211. DOI: 10.1016/0742-8413(91)90155-M.

Konrad R., Ferry N., Gatehouse AMR., Babendreier D. 2008. Potential Effects of Oilseed Rape Expressing Oryzacystatin-1 (OC-1) and of Purified Insecticidal Proteins on Larvae of the Solitary Bee Osmia bicornis. PLoS ONE 3:e2664. DOI: 10.1371/journal.pone.0002664.

Krupke CH., Hunt GJ., Eitzer BD., Andino G., Given K. 2012. Multiple routes of pesticide exposure for honey bees living near agricultural fields. PloS one 7:e29268-e29268. DOI: 10.1371/journal.pone.0029268.

Long EY., Krupke CH. 2016. Non-cultivated plants present a season-long route of pesticide exposure for honey bees. Nature Communications 7:11629. DOI: 10.1038/ncomms11629.

Lundin O., Rundlof M., Smith HG., Fries I., Bommarco R. 2015. Neonicotinoid insecticides and their impacts on bees: A systematic review of research approaches and identification of knowledge gaps. PLoS ONE 10:1-20. DOI: 10.1371/journal.pone.0136928.

Moffat C., Pacheco JG., Sharp S., Samson AJ., Bollan KA., Huang J., Buckland ST., Connolly CN. 2015. Chronic exposure to neonicotinoids increases neuronal vulnerability to mitochondrial dysfunction in the bumblebee (Bombus terrestris). FASEB journal : official publication of the Federation of American Societies for Experimental Biology 29:2112-9. DOI: 10.1096/fj.14-267179.

Mogren CL., Lundgren JG. 2016. Neonicotinoid-contaminated pollinator strips adjacent to cropland reduce honey bee nutritional status. Nature Publishing Group:1-10. DOI: 10.1038/srep29608.

Mullin CA., Frazier M., Frazier JL., Ashcraft S., Simonds R., Vanengelsdorp D., Pettis JS. 2010. High levels of miticides and agrochemicals in North American apiaries: implications for honey bee health. PloS one 5:e9754-e9754.

Ollerton J., Erenler H., Edwards M., Crockett R. 2014. Pollinator declines. Extinctions of aculeate pollinators in Britain and the role of large-scale agricultural changes. Science (New York, N.Y.) 346:1360-2. DOI: 10.1126/science.1257259.

Palmer MJ., Moffat C., Saranzewa N., Harvey J., Wright GA., Connolly CN. 2013. Cholinergic pesticides cause mushroom body neuronal inactivation in honeybees. Nature Communications 4:1634. DOI: 10.1038/ncomms2648.

Peng Y-C., Yang E-C. 2016. Sublethal Dosage of Imidacloprid Reduces the Microglomerular Density of Honey Bee Mushroom Bodies. Scientific reports 6:19298. DOI: 10.1038/srep19298.

Peters B., Gao Z., Zumkier U. 2016. Large-scale monitoring of effects of clothianidin-dressed oilseed rape seeds on pollinating insects in Northern Germany: effects on red mason bees (Osmia bicornis). Ecotoxicology 25:1679-1690. DOI: 10.1007/s10646-016-1729-4.

Piiroinen S., Goulson D. 2016. Chronic neonicotinoid pesticide exposure and parasite stress differentially affects learning in honeybees and bumblebees. Proceedings. Biological sciences / The Royal Society 283:20160246. DOI: 10.1098/rspb.2016.0246.

Pisa LW., Amaral-Rogers V., Belzunces LP., Bonmatin JM., Downs CA., Goulson D., Kreutzweiser DP., Krupke C., Liess M., McField M., Morrissey C a., Noome D a., Settele J., Simon-Delso N., Stark JD., Van der Sluijs JP., Van Dyck H., Wiemers M. 2014. Effects of neonicotinoids and fipronil on non-target invertebrates. Environmental science and pollution research international 22:1-35. 
634

635

636

637

638

639

640

641

642

643

644

645

646

647

648

649

650

651

652

653

654

655

656

657

658

659

660

661

662

663

664

665

666

667

668

669

670

671

672

673

674

675

676

677

678

679

Radmacher S., Strohm E. 2011. Effects of constant and fluctuating temperatures on the development of the solitary bee Osmia bicornis (Hymenoptera: Megachilidae). Apidologie 42:711-720. DOI: 10.1007/s13592-011-0078-9.

Raw A. 1972. The biology of the solitary bee Osmia rufa (L.) (Megachilidae). Transactions of the Royal Entomological Society of London 124:213-229. DOI: 10.1111/j.13652311.1972.tb00364.x.

Rondeau G., Sánchez-Bayo F., Tennekes H a., Decourtye A., Ramírez-Romero R., Desneux N. 2014. Delayed and time-cumulative toxicity of imidacloprid in bees, ants and termites. Scientific reports 4:5566. DOI: 10.1038/srep05566.

Rortais A., Arnold G., Halm M., Touffet-Briens F. 2005. Modes of honeybees exposure to systemic insecticides : estimated amounts of contaminated pollen and nectar consumed by different categories of bees. Apidologie 36:71-83. DOI: 10.1051/apido.

Rosa A de S., Teixeira JSG., Vollet-Neto A., Queiroz EP., Blochtein B., Pires CSS., ImperatrizFonseca VL. 2016. Consumption of the neonicotinoid thiamethoxam during the larval stage affects the survival and development of the stingless bee, Scaptotrigona aff. depilis. Apidologie 47:729-738. DOI: 10.1007/s13592-015-0424-4.

Rundlöf M., Andersson GKS., Bommarco R., Fries I., Hederström V., Herbertsson L., Jonsson O., Klatt BK., Pedersen TR., Yourstone J., Smith HG. 2015. Seed coating with a neonicotinoid insecticide negatively affects wild bees. Nature 521:77-80. DOI: 10.1038/nature14420.

Sanchez-Bayo F., Goka K. 2014. Pesticide residues and bees--a risk assessment. PloS one 9:e94482-e94482. DOI: 10.1371/journal.pone.0094482.

Sandrock C., Tanadini LG., Pettis JS., Biesmeijer JC., Potts SG., Neumann P. 2014a. Sublethal neonicotinoid insecticide exposure reduces solitary bee reproductive success. Agricultural and Forest Entomology 16:119-128. DOI: 10.1111/afe.12041.

Sandrock C., Tanadini M., Tanadini LG., Fauser-Misslin A., Potts SG., Neumann P. $2014 b$. Impact of chronic neonicotinoid exposure on honeybee colony performance and queen supersedure. PloS one 9:e103592-e103592. DOI: 10.1371/journal.pone.0103592.

Scott-dupree ACD., Conroy L., Harris CR. 2009. Impact of Currently Used or Potentially Useful Insecticides for Canola Agroecosystems on Bombus impatiens ( Hymenoptera: Apidae ), Megachile rotundata ( Hymentoptera : Megachilidae), and Osmia lignaria ( Hymenoptera : Megachilidae ) Impact of Currently .

Sgolastra F., Bosch J., Molowny-Horas R., Maini S., Kemp WP. 2010. Effect of temperature regime on diapause intensity in an adult-wintering Hymenopteran with obligate diapause. Journal of Insect Physiology 56:185-194. DOI: 10.1016/j.jinsphys.2009.10.001.

Sgolastra F., Kemp WP., Buckner JS., Pitts-Singer TL., Maini S., Bosch J. 2011. The long summer: Pre-wintering temperatures affect metabolic expenditure and winter survival in a solitary bee. Journal of Insect Physiology 57:1651-1659. DOI: 10.1016/j.jinsphys.2011.08.017.

Sgolastra F., Medrzycki P., Bortolotti L., Renzi MT., Tosi S., Bogo G., Teper D., Porrini C., Molowny-Horas R., Bosch J. 2016. Synergistic mortality between a neonicotinoid insecticide and an ergosterol-biosynthesis-inhibiting fungicide in three bee species. Pest Management Science. DOI: 10.1002/ps.4449.

Simon-Delso N., Amaral-Rogers V., Belzunces LP., Bonmatin JM., Chagnon M., Downs C., Furlan L., Gibbons DW., Giorio C., Girolami V., Goulson D., Kreutzweiser DP., Krupke CH., Liess M., Long E., McField M., Mineau P., Mitchell EAD., Morrissey CA., Noome

PeerJ reviewing PDF | (2017:03:16659:1:1:REVIEW 3 May 2017) 
680

681

682

683

684

685

686

687

688

689

690

691

692

693

694

695

696

697

698

699

700

701

702

703

704

705

706

707

708

709

710

711

712

713

714

715

716

717

718

719

720

721

722

723

724

725
DA., Pisa L., Settele J., Stark JD., Tapparo A., Van Dyck H., Van Praagh J., Van der Sluijs JP., Whitehorn PR., Wiemers M. 2014. Systemic insecticides (neonicotinoids and fipronil): trends, uses, mode of action and metabolites. Environmental Science and Pollution Research. DOI: 10.1007/s11356-014-3470-y.

Sláma K., Miller TA. 1987. Insecticide poisoning: Disruption of a possible autonomic function in pupae of Tenebrio molitor. Pesticide Biochemistry and Physiology 29:25-34. DOI: 10.1016/0048-3575(87)90081-2.

Stanley DA., Smith KE., Raine NE., Schafer S., Pham-Delègue M-H. 2015. Bumblebee learning and memory is impaired by chronic exposure to a neonicotinoid pesticide. Scientific Reports 5:16508. DOI: $10.1038 /$ srep16508.

Suchail S., Guez D., Belzunces LP. 2001. Discrepancy between acute and chronic toxicity induced by imidacloprid and its metabolites in Apis mellifera. Environmental toxicology and chemistry / SETAC 20:2482-2486.

Tan K., Chen W., Dong S., Liu X., Wang Y., Nieh JC. 2015. A neonicotinoid impairs olfactory learning in Asian honey bees (Apis cerana) exposed as larvae or as adults. Scientific Reports 5:10989. DOI: 10.1038/srep10989.

Terblanche JS., White CR., Blackburn TM., Marais E., Chown SL. 2008. Scaling of gas exchange cycle frequency in insects. Biol. Lett 4:127-129. DOI: 10.1098/rsb1.2007.0522.

Thany SH., Gauthier M. 2005. Nicotine injected into the antennal lobes induces a rapid modulation of sucrose threshold and improves short-term memory in the honeybee $<\mathrm{i}>$ Apis mellifera $</ \mathrm{i}>$. Brain research 1039:216-219.

Thany SH., Lenaers G., Crozatier M., Armengaud C., Gauthier M. 2003. Identification and localization of the nicotinic acetylcholine receptor alpha3 mRNA in the brain of the honeybee, Apis mellifera. Insect Molecular Biology 12:255-262. DOI: 10.1046/j.13652583.2003.00409.x.

Tomé HV V., Barbosa WF., Martins GF., Guedes RNC. 2015. Spinosad in the native stingless bee Melipona quadrifasciata: Regrettable non-target toxicity of a bioinsecticide. Chemosphere 124:103-109. DOI: 10.1016/j.chemosphere.2014.11.038.

Tomé HV V., Martins GF., Lima MAP., Campos LAO., Guedes RNC. 2012. Imidaclopridinduced impairment of mushroom bodies and behavior of the native stingless bee Melipona quadrifasciata anthidioides. PloS one 7:e38406. DOI: 10.1371/journal.pone.0038406.

Tomizawa M., Casida JE. 2005. Neonicotinoid insecticide toxicology: mechanisms of selective action. Annual review of pharmacology and toxicology 45:247-268. DOI: 10.1146/annurev.pharmtox.45.120403.095930.

Vanbergen AJ. 2013. Threats to an ecosystem service: pressures on pollinators. Frontiers in Ecology and the Environment:251-259.

Williamson SM., Wright GA. 2013. Exposure to multiple cholinergic pesticides impairs olfactory learning and memory in honeybees. The Journal of experimental biology 216:1799-1807. DOI: 10.1242/jeb.083931.

Woodcock BA., Isaac NJB., Bullock JM., Roy DB., Garthwaite DG., Crowe A., Pywell RF. 2016. Impacts of neonicotinoid use on long-term population changes in wild bees in England. Nature Communications 7:12459. DOI: 10.1038/ncomms12459.

Wu JY., Anelli CM., Sheppard WS. 2011. Sub-lethal effects of pesticide residues in brood comb on worker honey bee (Apis mellifera) development and longevity. PloS one 6:e14720e14720. DOI: 10.1371/journal.pone.0014720.

Yang EC., Chang HC., Wu WY., Chen YW. 2012. Impaired olfactory associative behavior of 
726 honeybee workers due to contamination of imidacloprid in the larval stage. PLOS ONE $727 \quad 7: \mathrm{e} 49472$.

728 Yocum GD., Greenlee KJ., Rinehart JP., Bennett MM., Kemp WP. 2011. Cyclic CO2 emissions during the high temperature pulse of fluctuating thermal regime in eye-pigmented pupae of Megachile rotundata. Comparative Biochemistry and Physiology Part A: Molecular \& Integrative Physiology 160:480-485. DOI: 10.1016/j.cbpa.2011.08.004.

Zafeiridou G., Theophilidis G. 2004. The action of the insecticide imidacloprid on the respiratory rhythm of an insect: the beetle Tenebrio molitor. DOI: 10.1016/j.neulet.2004.04.084. 


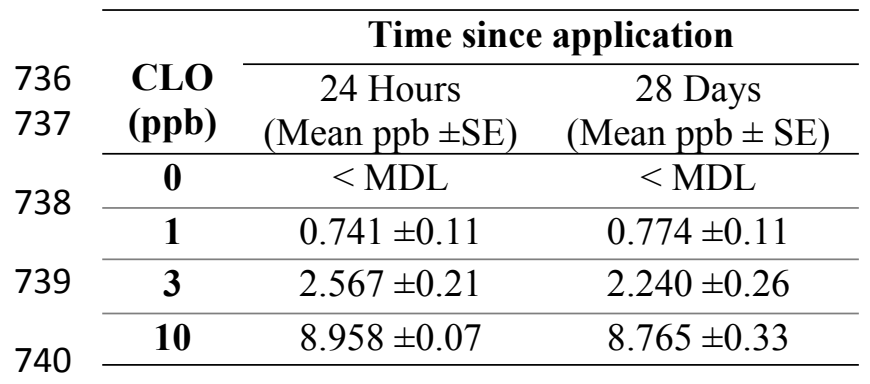

741 Table 1 Concentration of clothianidin detected in pollen provisions, 24 hours and 28 days after 742 spiking provisions. Provisions were incubated under the same conditions as bees $(n=3$ per 743 treatment per time point, $\mathrm{MDL}=$ Method Detection Limit, $\mathrm{SE}=$ Standard Error). 


\begin{tabular}{|c|c|c|c|c|c|c|c|c|c|}
\hline \multirow{3}{*}{$\begin{array}{l}\text { CLO } \\
(\mathrm{ppb})\end{array}$} & \multicolumn{4}{|c|}{ Larval Development and Survival } & \multicolumn{2}{|c|}{ Pupation Success } & \multicolumn{3}{|c|}{ Over-wintering Survival } \\
\hline & \multirow[t]{2}{*}{$\begin{array}{c}N \\
\text { Eggs }\end{array}$} & \multicolumn{2}{|c|}{$\begin{array}{c}\text { Development Time } \\
\text { (Days) }\end{array}$} & \multirow[t]{2}{*}{$\begin{array}{c}\% \\
\text { Mortality } \\
\text { (Larval) }\end{array}$} & \multirow[t]{2}{*}{$\begin{array}{c}N \\
\text { Cocoons }\end{array}$} & \multirow[t]{2}{*}{$\begin{array}{c}\% \\
\text { Mortality } \\
\text { (Pupal) }\end{array}$} & \multirow[t]{2}{*}{$\begin{array}{c}\% \\
\text { Mortality } \\
\text { (Overwinter) }\end{array}$} & $\begin{array}{c}N \\
\text { Emerged } \\
\text { Adults }\end{array}$ & \multirow[t]{2}{*}{$\begin{array}{c}\% \\
\text { Survival } \\
\text { (Overall) }\end{array}$} \\
\hline & & Mean $\pm S D$ & Range & & & & & $m \quad f$ & \\
\hline 0 & 31 & $31 \pm 5$ & $24-41$ & 6.45 & 29 & 13.79 & 8.80 & 14 & 70.97 \\
\hline 1 & 33 & $31 \pm 4$ & $23-39$ & 9.09 & 30 & 6.67 & 7.14 & 14 & 78.78 \\
\hline 3 & 38 & $30 \pm 4$ & $24-42$ & 9.21 & 35 & 5.71 & 6.06 & 15 & 81.58 \\
\hline 10 & 36 & $32 \pm 4$ & $21-38$ & 8.88 & 32 & 6.25 & 0.00 & 14 & 83.33 \\
\hline
\end{tabular}

777

778

779

780

781

782

783

784

785

786

787

788

789

790

791

792

793

794

795

796

797

798

799
Table 2 Development time and larval, pupal and overwintering survival rates of Osmia bicornis reared on pollen provisions spiked with different concentrations of clothianidin. 
800

801

802

803

804

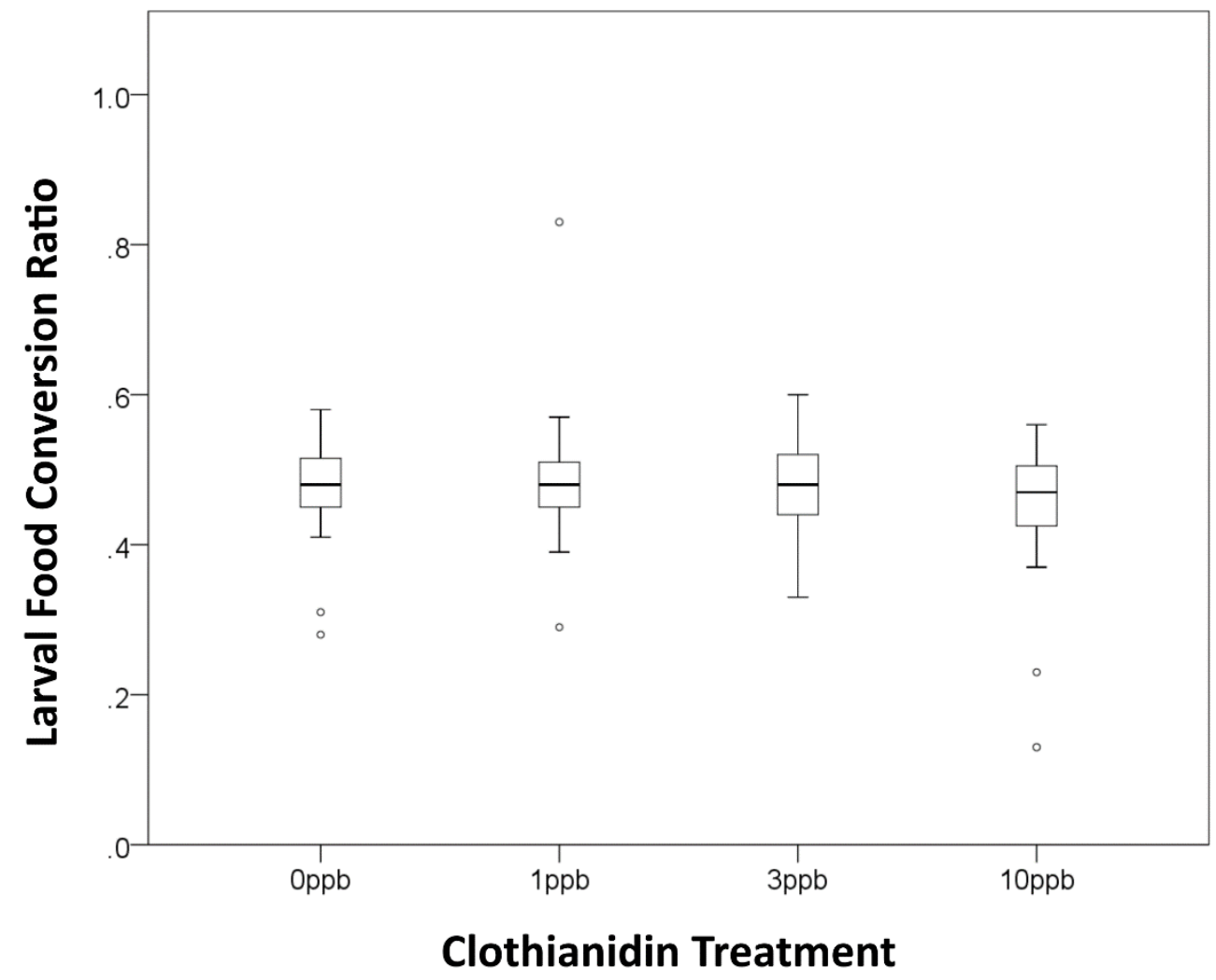

805

806 Figure 1 Efficiency with which bees converted pollen provision mass into larval body mass

807 (median and interquartile range). Pollen provisions were spiked with clothianidin at one of four 808 doses $(0 p p b n=29 ; 1 p p b n=30 ; 3 p p b n=35 ; 10 p p b n=32)$. There was no difference in larval 809 body mass between treatments.

810

811

812

813

814 

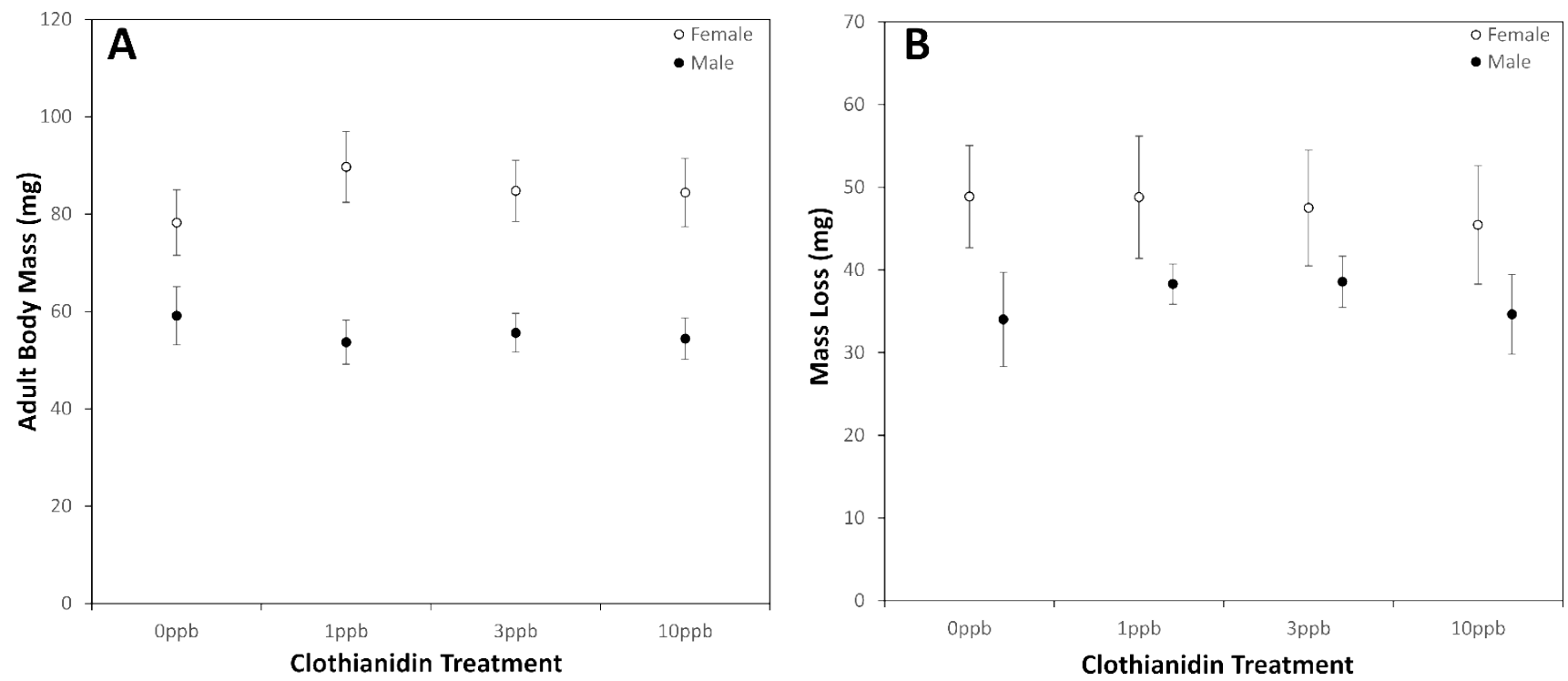

830

831

832

Figure 2 (A) Emergent adult body mass and (B) absolute mass loss over winter (pre-pupa to 833 adult) for female (open circles, $n=58$ ) and male (black circles, $n=51$ ) bees exposed to pollen 834 spiked with clothianidin during larval development at one of four doses (Mean $\pm 95 \%$ confidence 835 interval $(\mathrm{CI}) ; 0 \mathrm{ppb} \mathrm{m}=8, \mathrm{f}=14 ; 1 \mathrm{ppb} \mathrm{m}=14, \mathrm{f}=12 ; 3 \mathrm{ppb} \mathrm{m}=15, \mathrm{f}=16 ; 10 \mathrm{ppb} \mathrm{m}=14, \mathrm{f}=16)$. Data 836 in (A) are least-square means estimated by an ANCOVA performed for each sex, with treatment 
837 as a main effect and log-transformed pollen mass as a co-variate (Females provision weight= $838325.69 \mathrm{mg}$, Males=222.23 mg).

839

840

841

842

843

844

845

846

847

848

849

850

851

852
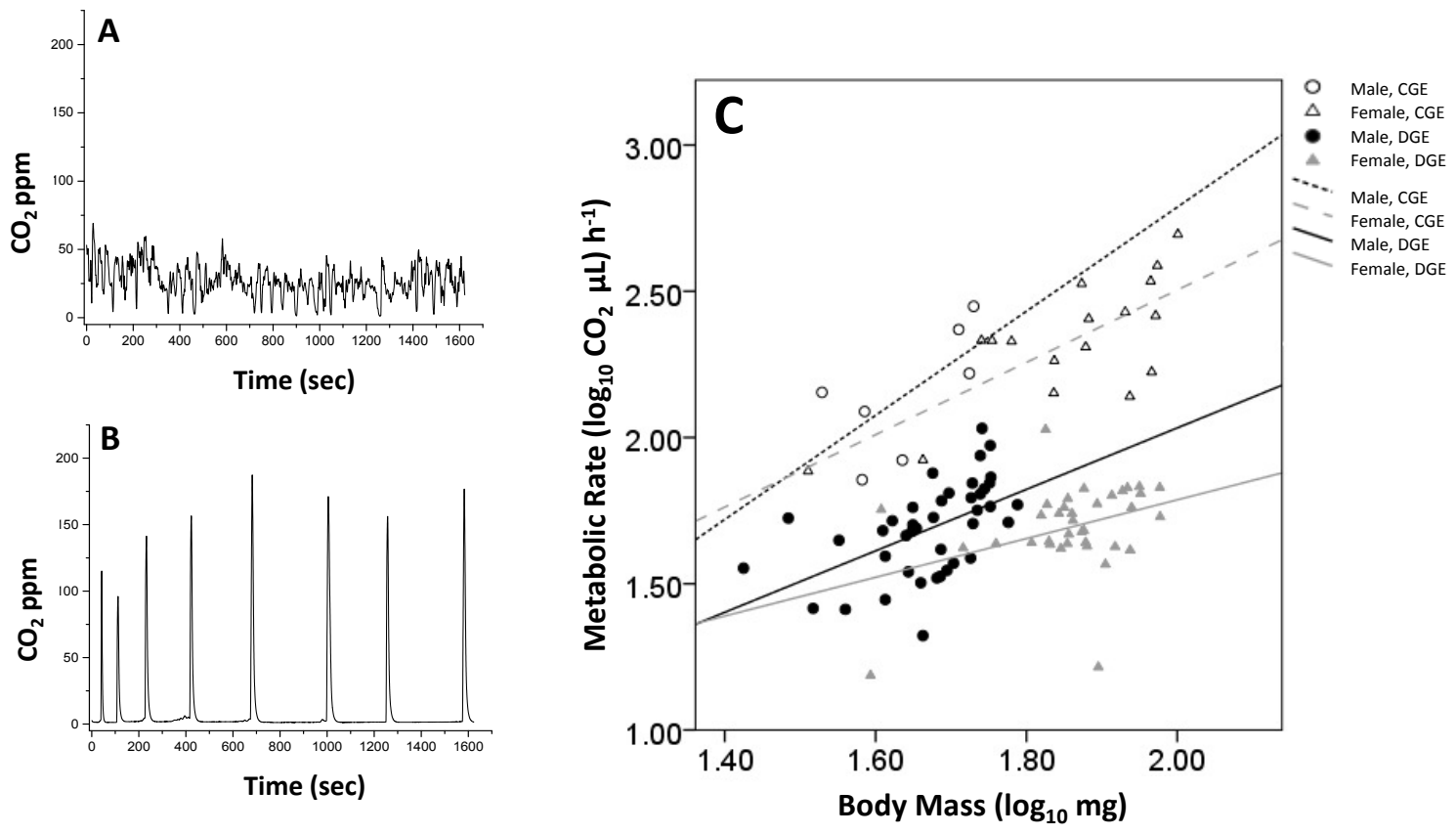

853

Figure 3 Example of continuous (A) and discontinuous patterns of gas exchange (B). Scaling 855 relationship between metabolic rate and body mass for male (circles) and female (triangles) bees

856 engaged in continuous (CGE, open shapes) versus discontinuous (DGE, filled shapes) gas 857 exchange $(\mathrm{C})$.

858 
860

861

862

863

864

865

866

867

868

869

870

871

872

873

Sex

$\begin{array}{ccc}\text { Gas Exchange } & \log _{10} & \log _{10} \\ \text { Slope } & \text { Intercept }\end{array}$

Mass scaling relationship

Regression Equation

\begin{tabular}{cllllll}
\hline Male & Continuous (CGE) & 1.78 & -0.77 & $\mathrm{MR}=0.170 \times \mathrm{M}^{1.78}$ & $\mathrm{R}^{2}=0.432, \mathrm{~F}_{1,6}=3.804$, & $\mathrm{p}=0.109$ \\
& Discontinuous (DGE) & 1.05 & -0.07 & $\mathrm{MR}=0.851 \times \mathrm{M}^{1.05}$ & $\mathrm{R}^{2}=0.278, \mathrm{~F}_{1,40}=15.021$, & $\mathrm{p}<0.001$ \\
& & 1.24 & 0.03 & $\mathrm{MR}=1.072 \times \mathrm{M}^{1.24}$ & $\mathrm{R}^{2}=0.557, \mathrm{~F}_{1,16}=18.837$, & $\mathrm{p}<0.001$ \\
\multirow{2}{*}{ Female } & Continuous (CGE) & 0.66 & 0.46 & $\mathrm{MR}=2.884 \times \mathrm{M}^{0.66}$ & $\mathrm{R}^{2}=0.136, \mathrm{~F}_{1,35}=5.374$, & $\mathrm{p}=0.027$ \\
& Discontinuous (DGE) & 0.66 & &
\end{tabular}

874

875 Table 3 Scaling relationship between wet body mass and metabolic rate for male and female bees

876 engaged in continuous and discontinuous gas exchange.

877

878

879

880

881

882

883

884

885

886

887

888

889 
890

891

892

893

894

895

896

897

898

899

900

901

902

903

904

905

906

907

908

909

910

911

912

913

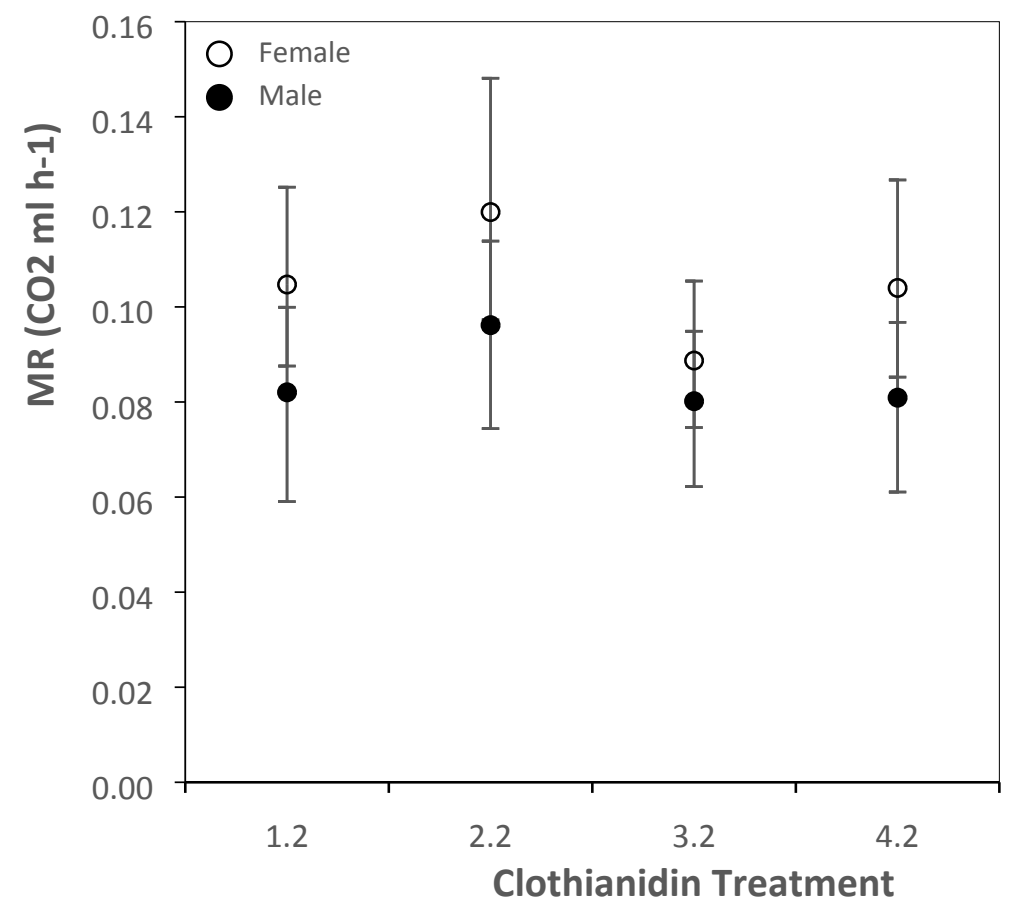


916 Figure 4 Metabolic rate for male (black circles, $n=48$ ) and female bees (open circles, $n=54$ )

917 exposed to varying concentrations of clothianidin during development. Data are least-square 918 means $( \pm \mathrm{CI})$ estimated by an ANCOVA performed for each sex, with treatment and gas 919 exchange pattern as a main effect and log-transformed adult body mass as a co-variate (Females= $92072.03 \mathrm{mg}$, Males $=46.57 \mathrm{mg}$ ).

921

922

923

924

925

926

927

928

929

930

931

932

933

934

935 